\title{
Compressive mononeuropathy of the deep palmar branch of the ulnar nerve in cyclists
}

\author{
GRAEME J HANKEY, SASSON S GUBBAY \\ From the Department of Neurology, Royal Perth Hospital, Perth, Western Australia
}

SUMMARY Two cyclists developed mononeuropathy of the deep palmar branch of the ulnar nerve due to ulnar nerve compression adjacent to the ulnar tunnel (of Guyon) by prolonged bicycle riding. A modification of hand grip on the bicycle handlebars resulted in rapid recovery in one patient.

With increasing public interest in physical fitness and, more specifically triathlon events, it can be anticipated that physical complications may arise. Cyclists training for the triathlon event may cycle for up to four hours a day, with the palms of the hands constantly applied to the bicycle handlebars. It is not unreasonable to expect therefore that compression neuropathies in the palm of the hand may occur.

We report two cyclists who have each presented with a compressive neuropathy of the deep palmar branch of the ulnar nerve which improved following a modification of handgrip on the bicycle handlebars.

\section{Case reports}

Case No 1 A 22 year old sportswoman presented with a 4 month history of progressive constant weakness of the fingers of the right hand resulting in difficulty with fine finger movements. She is a triathlete who cycles wherever she goes for up to four hours per day. Her mother has a past history of bilateral ulnar nerve decompressions at the elbow.

Examination revealed a strongly built young woman who had considerable wasting of the right hypothenar eminence, medial right thenar eminence and right first dorsal interosseous muscle. A red mark was still present over the hypothenar eminence bilaterally as a result of the pressure from gripping the handlebars of her bicycle on her way to the Consulting Room. (fig 1) Weakness was confined to abduction and adduction of the right fingers and adduction of the right thumb; sparing opposition and abduction of the thumb. The muscle bulk of the left hand was normal but abduction of the left little finger was weak as was adduction of the other

Address for reprint requests: Dr S S Gubbay, Department of Neurology, Royal Perth Hospital, GPO Box X2213, Perth 6001, Australia.

Received 15 January 1988 and in revised form 29 June 1988. Accepted 1 July 1988 fingers. Sensation was preserved and there was no ulnar nerve tenderness. The remainder of the examination was normal. Right and left median and ulnar nerve sensory conduction and median motor conduction studies were normal. Electromyograms of ulnar innervated muscles in the hand and the corresponding distal motor latencies are shown in table 1.

Table 1 EMGs and distal motor latencies

\begin{tabular}{|c|c|c|c|}
\hline Case & Muscle & $\begin{array}{l}\text { Distal latency } \\
\text { (ms) }\end{array}$ & $E M G$ \\
\hline 2 (Preoperative) & $\begin{array}{l}\text { R ADM } \\
\text { R lst DI } \\
\text { L ADM } \\
\text { L lst DI } \\
\text { R ADM } \\
\text { R Ist DI } \\
\text { R ADD POLL }\end{array}$ & $\begin{array}{l}2.4 \text { (Normal) } \\
5.2 \text { (Prolonged) } \\
2.8 \text { (Normal) } \\
4.3 \text { (Borderline) } \\
4.8 \text { (Prolonged) } \\
7.8 \text { (Prolonged) } \\
\quad \text { - }\end{array}$ & $\begin{array}{l}\text { Normal } \\
\text { Denervation } \\
\text { Normal } \\
\text { Denervation } \\
\text { Denervation } \\
\text { Denervation } \\
\text { Denervation }\end{array}$ \\
\hline
\end{tabular}

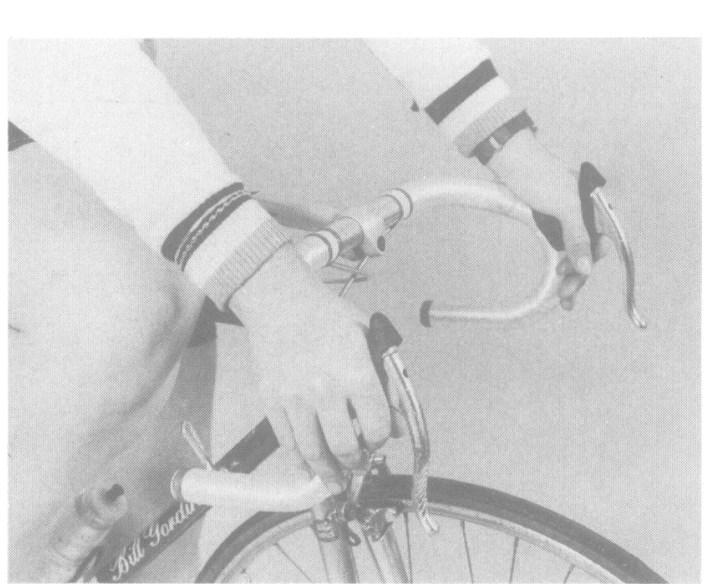

Fig 1 "Side-on" view of hand position of handlebars of bicycle showing palmar compression over Guyon's canal 




Fig 2 Right hand showing severe wasting of dorsal interossei, adductor pollicis, palmar interossei and hypothenar eminence.

Denervation changes were seen also on needle examination of the left first dorsal interosseous. The right abductor digiti minimi, left abductor pollicis brevis and abductor digiti minimi were normal.

The patient was diagnosed as having a compressive neuropathy of the deep branch of the ulnar nerve at the wrist bilaterally and was advised to modify her bicycle handgrip. Six weeks later she had recovered full power and function of her hands apart from minimal wasting of the right first dorsal interosseous and medial right thenar eminence and mild weakness of the right adductor pollicis and left abductor digiti minimi.

Case No 2 In 1982, a 21 year old medical technologist became aware of progressive wasting and weakness of the intrinsic muscles of the right hand. He had been an active sportsman, riding a bicycle for one to two hours per day since 1974.

Abnormalities on examination were confined to the right upper limb where severe wasting and moderate weakness of the right palmar and dorsal interossei, hypothenar eminence and median thenar eminence was present. (fig 2) Palpation over the right pisiform bone elicited tenderness. Orthodromic right median and ulnar sensory nerve action potentials were of normal distal latency and amplitude. The right median nerve motor distal latency and forearm motor conduction velocity was normal. Electromyograms of ulnar innervated muscles in the hand and the corresponding distal motor latencies are given in table 1.

The patient's symptoms and signs persisted and in July 1986 he underwent decompression of the right ulnar nerve in the palm and at the wrist. Despite a distinct clinical improvement in right hand function, further nerve conduction studies in March 1987 now showed impaired right ulnar nerve sensory function with orthodromic sensory nerve action potential distal latency from little finger to wrist to be $3.9 \mathrm{~m} / \mathrm{s}$. (normal $2 \cdot 1-3.0$ ) and amplitude $1 \cdot 1 \mu$ volts. The right ulnar nerve motor distal latency from the wrist to abductor digiti minimi was now $9.2 \mathrm{~m} / \mathrm{s}$. The ulnar nerve forearm conduction velocity was $63 \mathrm{~m} / \mathrm{s}$.

\section{Discussion}

The first patient developed a compressive neuropathy of the deep branch of the ulnar nerve at the wrist bilaterally due to prolonged pressure on the nerve with constant bicycle riding. A modification of her bicycle handgrip to avoid nerve compression resulted in a rapid and almost complete recovery. The second cyclist however, has a more severe neuropathy which has not resolved following decompression, a change in bicycle handgrip or cessation of bicycle riding. The 
Table 2 Syndromes of ulnar nerve compression in the wrist and hand

\begin{tabular}{|c|c|c|c|}
\hline Type & Site of compression & Motor & Sensory \\
\hline 1 & Just proximal to or in Guyon's canal & All ulnar innervated hand muscles & $\begin{array}{l}\text { Palmar surfaces of ulnar } 1 \frac{1}{2} \text { fingers and } \\
\text { hypothenar area }\end{array}$ \\
\hline 2 & $\begin{array}{l}\text { Superficial terminal branch in or just } \\
\text { distal to Guyon's canal }\end{array}$ & Nil & As above \\
\hline 3 & $\begin{array}{l}\text { Deep terminal branch before branches } \\
\text { to hypothenar muscles }\end{array}$ & All ulnar innervated hand muscles & Nil \\
\hline 4 & $\begin{array}{l}\text { Compression of deep branch after } \\
\text { origin of branches to hypothenar } \\
\text { muscles }\end{array}$ & $\begin{array}{l}\text { All except hypothenar ulnar } \\
\text { innervated hand muscles }\end{array}$ & Nil \\
\hline
\end{tabular}

localisation of the lesion is almost certainly adjacent to the ulnar tunnel (tunnel of Guyon) at the wrist and although clinical improvement is apparent the electrophysiological indices have deteriorated. Table 2 summarises the four different clinical syndromes which may result from compression of the ulnar nerve in the wrist and hand..$^{1-3}$

The second case had severe denervation in the right first dorsal interosseous and right adductor pollicis muscle but mild to moderate denervation in right abductor digiti minimi consistent with involvement of the deep terminal branch before it supplies the branches to the hypothenar muscles.

Exclusive entrapment of the deep terminal motor fibres of the ulnar nerve just distal to Guyon's canal has been called the Ramsay-Hunt syndrome after Hunt's description in $1908 .^{4}$ The Ramsay-Hunt syndrome is frequently caused by trauma or chronic micro-trauma due to pressure of tools in different occupations, ${ }^{1256}$ but has also been described in the French and German literature to occur in cyclists. ${ }^{7-9}$ Since 1975, five cases of "cyclists palsy" have been described in the English literature, three of whom were studied neurophysiologically. ${ }^{10} 11$

With increasing public interest and participation in long distance cycling it is anticipated that the syndrome of compressive mononeuropathy of the deep palmar branch of the ulnar nerve will become more apparent. A careful history and demonstration by the patient of the manner in which the bicycle handlebars are gripped whilst mounted should aid in the diagnosis and facilitate advice to modify the bicycle handgrip.

\section{References}

1 Ebeling P, Gilliatt RW, Thomas PK. A clinical and electrical study of ulnar nerve lesions in the hand. $J$ Neurol Neurosurg Psychiatry. 1960;23:1.

2 Shea JD, McClain EJ. Ulnar nerve compression syndromes at and below the wrist. $J$ Bone Joint Surg 1969;51A:1095.

3 Uriburu IJF, Morchio FJ Marin JC. Compression syndrome of the deep motor branch of the ulnar nerve (piso-hamate hiatus syndrome). J Bone Joint Surg 1976;58A:145-7.

4 Hunt JR. Occupation neuritis of the deep palmar branch of the ulnar nerve. A well defined clinical type of professional palsy of the hand. J Nerv Ment Dis 1908;35:673.

5 Bakke JL, Wolff HG. Occupational pressure neuritis of the deep palmar branch of the ulnar nerve. Arch Neurol Psychiatry 1948;60:549-53.

6 Magee RK. Neuritis of the deep palmar branch of the ulnar nerve. Arch Neurology, Psychiatry (Chicago) 1955;73:200-2.

7 Stiefler G. Uber die Radfahrelahmung des Nervus Ulnaris. Munch Med Wschr 1927;42:1796-7.

8 Guillain G, Bourguignon G, Corre L. Les paralysies du nerf cubital chez les cyclistes. Bull Soc Med Hop Paris 1940;56:489-92.

9 Lereboullet J, Lindeux S. La paralysie cubitale des cyclistes. Paris Med 1942;40/41:315-6.

10 Eckman PB, Perlstein G, Altrocchi PH. Ulnar neuropathy in bicycle riders. Arch Neurol (Chic) 1975; 32:130-1.

11 North J, Dietz V, Mauritz KH. Cyclists' palsy. Neurological and EMG study in four cases with distal ulnar lesions. J Neurol Sci 1980;47:111-6. 